\title{
Genomic Epidemiology of Azithromycin-Nonsusceptible Neisseria gonorrhoeae, Argentina, 2005-2019
}

Ricardo Ariel Gianecini, Tomas Poklepovich, Daniel Golparian, Noelia Cuenca,

Ezequiel Tuduri, Magnus Unemo, Josefina Campos, Patricia Galarza, Gonococcal Antimicrobial Susceptibility Surveillance Programme-Argentina ${ }^{1}$

\begin{abstract}
Azithromycin-nonsusceptible Neisseria gonorrhoeae strains are an emerging global public health threat. During 2015-2018, the prevalence of azithromycin-nonsusceptible gonococcal infection increased significantly in Argentina. To investigate the genomic epidemiology and resistance mechanisms of these strains, we sequenced 96 nonsusceptible isolates collected in Argentina during 2005-2019. Phylogenomic analysis revealed 2 main clades, which were characterized by a limited geographic distribution, circulating during January 2015-November 2019. These clades included the internationally spreading multilocus sequence types (STs) 1580 and 9363 . The ST1580 isolates, which had MICs of $2-4 \mu \mathrm{g} / \mathrm{mL}$, had mutations in the 23S rRNA. The ST9363 isolates, which had MICs of $2-4$ or $\geq 256 \mu \mathrm{g} / \mathrm{mL}$, had mutations in the $23 S$ rRNA, a mosaic $m t r$ locus, or both. Identifying the geographic dissemination and characteristics of these predominant clones will guide public health policies to control the spread of azithromycin-nonsusceptible $N$. gonorrhoeae in Argentina.
\end{abstract}

Onorrhea, caused by infection with the bacteTrium Neisseria gonorrhoeae, is the second most prevalent bacterial sexually transmitted infection (STI) globally $(1,2)$. The World Health Organization (WHO) estimated that in 2016, a total of 86.9 million incident gonorrhea cases occurred among persons $15-49$ years of age, including 13.8 million cases in the

Authors affiliations: Instituto Nacional de Enfermedades Infecciosas-Administración Nacional de Laboratorios e Institutos de Salud Dr. Carlos G. Malbrán, Buenos Aires, Argentina (R.A. Gianecini, T. Poklepovich, N. Cuenca, E. Tuduri, J. Campos, P. Galarza); World Health Organization Collaborating Centre for Gonorrhoea and Other STIs, Örebro University, Örebro, Sweden (D. Golparian, M. Unemo)

DOI: https://doi.org/10.3201/eid2709.204843
WHO Region of the Americas (1). Researchers have documented antimicrobial resistance (AMR) to all drugs used to treat gonorrhea $(2,3)$. Ceftriaxone, an extended-spectrum cephalosporin, is the last option for first-line empirical treatment, but the emergence of ceftriaxone resistance has raised concerns about future treatments $(2,4)$. Consequently, WHO guidelines and national guidelines of many countries now recommend a combination of ceftriaxone $(250 \mathrm{mg}-$ $1 \mathrm{~g})$ and azithromycin (1-2 g) as first-line treatment for uncomplicated gonorrhea $(5,6)$. However, in 2016 Fifer et al. (7) reported the failure of dual therapy. Two years later, a gonococcal strain with ceftriaxone resistance and high-level azithromycin resistance was isolated in Australia and England (8-10). In recent years, international reports of azithromycin-resistant $N$. gonorrhoeae have substantially increased $(2,3,11,12)$. The WHO Global Gonococcal Antimicrobial Surveillance Program showed that in 2016, a total of $48.4 \%$ of reporting countries had an $>5 \%$ increase in rates of azithromycin resistance (3).

Argentina has reported low azithromycin resistance levels since the early 2000s (13). In Argentina, the proportion of azithromycin-nonsusceptible isolates (i.e., requiring MICs $>1 \mu \mathrm{g} / \mathrm{mL}$ ) increased from $0.1 \%$ in 2015 to $4.3 \%$ in $2018(\mathrm{p}<0.01)(14)$. The Clinical and Laboratory Standards Institute currently states a susceptible-only breakpoint for azithromycin (15); for simplicity, we refer to these isolates as resistant. High-level azithromycin-resistant isolates requiring MICs $\geq 256 \mu \mathrm{g} / \mathrm{mL}$ have emerged in several countries, including Argentina (16-20). Azithromycin resistance threatens the effectiveness of dual antimicrobial gonorrhea treatment.

${ }^{1}$ Members of this group are listed at the end of the article. 
Whole-genome sequencing (WGS) provides higher resolution and accuracy than other typing methods, making it an ideal method to study the dissemination and transmission dynamics of $N$. gonorrhoeae strains on a national and international level $(21,22)$. Furthermore, WGS data offer insights into AMR determinants, thereby enabling prediction, enhanced detection, and characterization of high-risk clones $(22,23)$. Several studies have found N. gonorrhoeae lineages and clones driving AMR transmission among $N$. gonorrhoeae strains within local, national, and international networks $(16,17,24-26)$. Genomic surveillance provides information on current and emerging trends of circulating strains. Phenotypic, epidemiologic, and genomic surveillance data are critical for designing public health interventions and treatment strategies. Genomic approaches, including molecular epidemiology and detection of AMR determinants, are crucial for monitoring resistance to firstline drugs. We examined the genomic background of azithromycin-resistant $N$. gonorrhoeae isolates with MICs $\geq 2 \mu \mathrm{g} / \mathrm{mL}$ collected throughout Argentina during 2005-2019.

\section{Materials and Methods}

We examined 96 azithromycin-resistant $N$. gonorrhoeae isolates (MICs $\geq 2 \mu \mathrm{g} / \mathrm{mL}$ ) from male and female patients treated at STI hospitals throughout Argentina. We selected 95 isolates from 8,002 consecutive isolates collected through the Gonococcal Antimicrobial Susceptibility Surveillance Programme-Argentina during January 2005-November 2019; we also included an isolate with high-level azithromycin resistance cultured in 2001 (20). We confirmed the N. gonorrhoeae species by culture on selective agar media, microscopic analysis using Gram staining, rapid oxidase positivity, superoxol test, carbohydrate utilization test, and matrix-assisted laser desorption/ ionization time-of-flight mass spectrometry (microflex LT/SH; Bruker Daltonik, https://www.bruker. com) (27). The study was approved by the Research Ethics Committee of the Hospital General de Agudos "Bernardino Rivadavia" (Buenos Aires, Argentina). MIC determinations and whole-genome sequencing for all isolates were conducted using methods previously described (Appendix, https://wwwnc.cdc. gov/EID/article/27/9/20-4843-App1.pdf).

\section{WGS Analysis}

We identified AMR determinants (i.e., the $m t r R-35 \mathrm{~A}$, $m t r_{120^{\prime}}$ and mosaic N. meningitidis-like $m t r R$ mutations) in addition to the MtrR A39T and G45D amino acid mutations in silico from WGS data, as described
$(26,28)$. We aligned and compared the $m t r$ locus and rplD, rplV, and macAB sequences with the N. gonorrhoeae FA1090 reference genome (GenBank accession no. AE004969). To identify the frequency of $23 \mathrm{~S}$ rRNA A2059G and C2611T mutations (named using Escherichia coli numbering), we mapped sequence reads against a single copy of the FA1090 23S rRNA gene using Burrow-Wheeler Aligner version 0.7.17 (http://bio-bwa.sourceforge.net) with the default settings. We determined base counts using a custom script, enabling the estimation of the proportion of copies with the A2059G, C2611T, or both mutations. We examined additional macrolide resistance genes (e.g., ere $A$, ere $B, \operatorname{erm} A, \operatorname{erm} B$, mef $A, m e f B, m s r A$, and $m s r C)$ using ARIBA version 2.14.4 and the ResFinder (https://cge.cbs.dtu.dk/services/ResFinder) and CARD (https://card.mcmaster.ca) databases (29). We identified alleles in silico from WGS data using $N$. gonorrhoeae multiantigen sequence typing (NGMAST), multilocus sequence typing (MLST), and $N$. gonorrhoeae sequence typing for antimicrobial resistance (NG-STAR). We used the MLST (https:// pubmlst.org/neisseria), NG-MAST (http://www. ng-mast.net), and NG-STAR (https://ngstar.canada.ca) databases to assign allele numbers and sequence types (ST)s $(30,31)$. We grouped closely related NG-MAST STs using a previously described genogroup definition (28).

For phylogenetic analysis, we identified singlenucleotide polymorphisms (SNPs) in sequence reads mapped against the WHO P reference genome using the variant calling tool Snippy version 4.4 .5 (https:/ / github.com/tseemann/snippy). We identified and filtered recombinant regions using Gubbins version 2.1.0 (Sanger, https:// sanger-pathogens.github.io/ gubbins); the resulting core SNP alignment consisted of 9,415 sites. We used IQ-tree version 1.6.1 (http:/ / www.iqtree.org) to infer a maximum-likelihood tree from the whole-genome SNP alignment with a generalized time-reversible model of evolution using gamma correction for among-site rate variation with 4 rate categories; branch support was estimated by bootstrap analysis of 10,000 replicates (32). We visualized the resulting phylogeny with Figtree version 1.4.4 (http:// tree.bio.ed.ac.uk/software/figtree) and phandango (33). We clustered sequences using RAMI with a branch length threshold of 0.01 (34). For comparison, we selected international isolates and publicly available genomic data on the basis of MICs, MLST STs (i.e., ST9363 and ST1580), and NG-MAST genogroups (i.e., G470 and G12302) from the National Center for Biotechnology Information (https:/ / www. ncbi.nlm.nih.gov), European Molecular Biology 
Laboratory (https://www.embl.org), and the DNA Data Bank of Japan (https://www.ddbj.nig.ac.jp). We found 17 genomes from the United Kingdom, 3 from Canada, 3 from Scotland, 17 from Australia, 28 from the United States, 7 from Brazil, and 11 from Norway $(16,17,24,25,35-37)$. We generated a phylogenetic tree of 86 international and 96 isolates from Argentina as described for domestic isolates and visualized the tree in Figtree version 1.4.4. Sequence reads are available from the European Nucleotide Archive (accession no. PRJEB41007).

\section{Results}

\section{Patient Data}

The 96 N. gonorrhoeae isolates were collected from male $(90.6 \%)$ and female (6.3\%) patients; sex was unreported for $3.1 \%$ of patients. Patient age was reported for $88(91.7 \%)$ isolates. Patients were $4-47$ years of age (mean 24.3 years of age); $79.5 \%$ were $<30$ years of age. In total, 72 isolates were cultured from the urethra, 11 from urine, 3 from the cervix, 2 from the vagina (in children 4 and 6 years of age), 1 from the pharynx, and 7 from an unreported site.

The isolates were collected in $7 / 24$ provinces. Among these, Córdoba and Ciudad Autónoma de Buenos Aires (CABA), 2 of the most populated provinces in Argentina, had the highest percentage of isolates (Córdoba had 47.9\%; CABA had 39.6\%) (Figure 1). We observed a lower percentage of isolates from the provinces of Buenos Aires (5.2\%), Rio Negro (3.1\%), Neuquén (2.1\%), La Pampa (1.0\%), and Santa Fe (1.0\%).

Antimicrobial Susceptibility of $\boldsymbol{N}$. gonorrhoeae Isolates Overall, $78(81.3 \%)$ isolates had azithromycin MICs of $2-4 \mu \mathrm{g} / \mathrm{mL}, 13$ (13.5\%) had MICs of 8-16 $\mu \mathrm{g} / \mathrm{mL}$, and $5(5.2 \%)$ had MICs of $\geq 256 \mu \mathrm{g} / \mathrm{mL}$ (Table 1$)$. Among 5 isolates with MICs $\geq 256 \mu \mathrm{g} / \mathrm{mL}, 3$ were collected in CABA in $2001(n=1)$ and $2019(n=2)$; the other 2 isolates were collected in Buenos Aires in 2018 and Córdoba in 2019. All 96 azithromycin-resistant isolates were susceptible to ceftriaxone, cefixime, and spectinomycin. However, 2 isolates collected in 2016 from Córdoba, each had a MIC of $4 \mu \mathrm{g} / \mathrm{mL}$, showed decreased susceptibility to ceftriaxone $(\mathrm{MIC}=0.06$ $\mu \mathrm{g} / \mathrm{mL})$ and cefixime $(\mathrm{MIC}=0.125 \mu \mathrm{g} / \mathrm{mL})($ Table 2$)$.

\section{Molecular AMR Determinants}

All 5 isolates with MICs of $\geq 256 \mu \mathrm{g} / \mathrm{mL}$ had the A2059G mutation in all $423 \mathrm{~S}$ rRNA alleles, whereas none of the 91 isolates with MICs of $2-16 \mu \mathrm{g} / \mathrm{mL}$ had this SNP (Table 1). Most (72; 75\%) isolates with MICs of 2-16 $\mu \mathrm{g} /$
$\mathrm{mL}$ had the 23S rRNA C2611T mutation. Nearly all (70; $97.2 \%$ ) of these isolates had the C2611T mutation in all $423 \mathrm{~S}$ rRNA alleles, except for 2 isolates: 1 with a single mutated allele that had a MIC of $4 \mu \mathrm{g} / \mathrm{mL}$ and 1 with 3 mutated alleles that had a MIC of $8 \mu \mathrm{g} / \mathrm{mL}$. Interspecies mosaics in the mtr locus (which encodes the tripartite MtrCDE efflux pump), as well as mutations in the $m$ trR promoter, coding region, or both, have been associated with increased azithromycin MICs (38-40). Among the $80(83.3 \%)$ isolates with $m$ trR mutations, 17 (17.7\%) had an $m$ trR-35A promoter deletion, 44 (45.8\%) had an MtrR G45D amino acid mutation, 1 (1.0\%) had an $m$ trR-35A deletion and MtrR G45D substitution, and 18 (18.8\%) had a mosaic N. meningitidis-like $m$ trR promoter. We did not identify any isolates with the $m t r_{120}$ mutation. Eighteen isolates, all of which had MICs of $2-4 \mu \mathrm{g} / \mathrm{mL}$, had no 235 rRNA mutations; however, 13 contained a mosaic $m t r R$ promoter and 5 had a $m t r R-35 \mathrm{~A}$ deletion. Among 18 isolates with mosaic $m$ trR promoters, $100 \%$ also had mosaic sequences in the $m t r D, 100 \%$ in $m t r C$, and $94.4 \%$ in $m t r E$ loci. Fifteen isolates with a mosaic $m t r D$ allele had sequences identical to the N. meningitidis-like mosaic previously described $(39,40) ; 2$ isolates had sequences sharing $97.8 \%$ identity and 1 had a sequence sharing $97.3 \%$ identity with the $N$. meningitidislike mosaic (Appendix Figure 1). Isolates containing a mosaic-like $m t r$ locus had MICs of $\geq 2$ to $\geq 256 \mu \mathrm{g} / \mathrm{mL}$. Isolates with MICs of $\geq 256 \mu \mathrm{g} / \mathrm{mL}$ also contained the 23S rRNA A2059G mutation.

We did not find any mutations associated with macrolide resistance in the $r p l D$ gene, which encodes ribosomal protein L4, or the rplV gene, which encodes ribosomal protein L22 (23). In addition, we did not find $A M R$ mutations in $m a c A B$, which encodes the MacA-MacB efflux pump, or the acquired macrolide resistance genes, ere, $m e f$, erm, $m p h$, and $m s r$ (38). An isolate that had a MIC of $2 \mu \mathrm{g} / \mathrm{mL}$ had an unclear resistance mechanism.

\section{Molecular Epidemiology and Phylogenomic Analysis}

Among the $96 \mathrm{~N}$. gonorrhoeae isolates, we observed 42 NG-MAST STs, including 21 new STs and 25 STs represented by single isolates. We found 24 isolates belonging to ST470, 7 belonging to ST20102, 6 belonging to ST696, 4 belonging to ST12302, and 4 belonging to ST20104. We found 3 NG-MAST genogroups comprising $\geq 3$ isolates: 33 belonged to G470, 10 belonged to G12302, and 10 belonged to G20102. We also documented 14 MLST STs, including 2 new STs and 8 STs represented by single isolates. We found 43 isolates belonging to ST1580, 14 belonging to ST1901, 14 belonging to ST9363, and 10 belonging to ST1584. NG-STAR showed 32 types, of which 11 were new and 20 were represented by single isolates. 


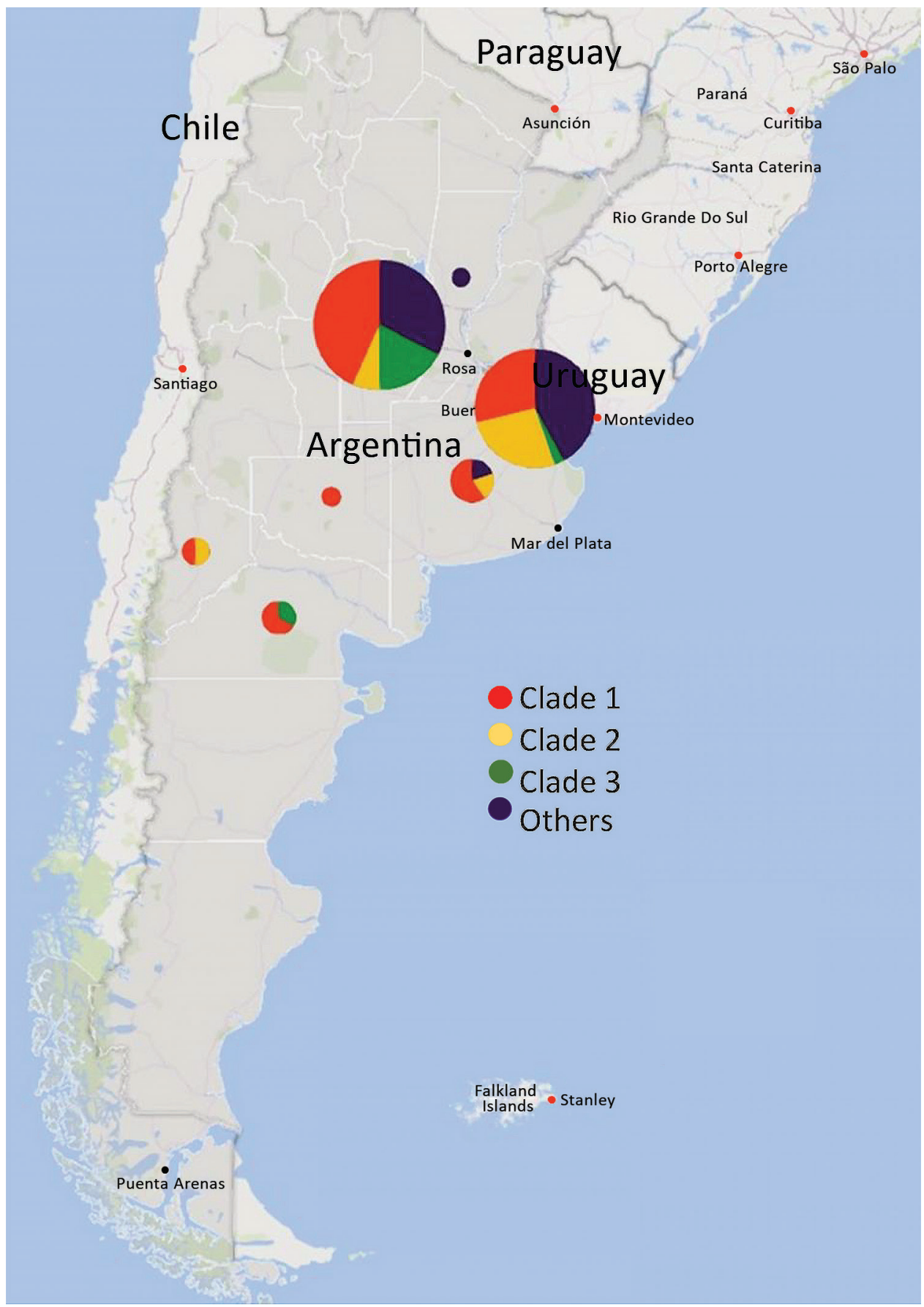

Figure 1. Geographic distribution of Neisseria gonorrhoeae isolates with azithromycin MICs of $\geq 2 \mu \mathrm{g} /$ $\mathrm{mL}$, Argentina, January 2005November 2019. Circle size corresponds to the number of isolates in each location. Circle colors indicate the proportion of isolates belonging to the 3 main genomic clades compared with other clades.

We found 32 isolates belonging to NG-STAR type 1038, 10 belonging to type 179,5 belonging to type 168 , and 5 belonging to type 3200 .

Analysis of the phylogenomic tree revealed 14 clades. In total, $63(65.6 \%)$ isolates were grouped into 3 clades, each containing 10-38 isolates (Figure 2) (https:/ / microreact.org/project/AZM_Project/006b822d). The remaining 33 isolates were singletons or belonged to smaller clonal groups of 2-6 isolates each.
Clade 1 comprised 38 isolates, most of which belonged to NG-MAST G470 (86.8\%), MLST ST1580 $(97.4 \%)$, or NG-STAR ST1038 (84.2\%). Clade 1 isolates had mean SNP difference of 8.5 (range 0-39). The isolates required MICs of $2-16 \mu \mathrm{g} / \mathrm{mL}$; most $(76.3 \%$; 29/38) required an MIC of $4 \mu \mathrm{g} / \mathrm{mL}$. The oldest isolate in clade 1 was identified in CABA in 2013. The proportion of clade 1 isolates increased significantly from $1.0 \%(1 / 96)$ in 2013 to $11.4 \%(11 / 96)$ in 2019 ( $p<0.05)$. Clade 1 was 
Table 1. Characteristics of 96 azithromycin-resistant Neisseria gonorrhoeae isolates, Argentina, January 2005-November 2019*

\begin{tabular}{|c|c|c|c|}
\hline \multirow[b]{2}{*}{ Characteristics } & \multicolumn{3}{|c|}{ MICs for azithromycin, $\mu \mathrm{g} / \mathrm{mL}$} \\
\hline & $2-4$ & $8-16$ & $\geq 256$ \\
\hline Total & 78 & 13 & 5 \\
\hline Province & $\begin{array}{c}\text { Buenos Aires, CABA, } \\
\text { Córdoba, Neuquén, La } \\
\text { Pampa, Río Negro, Santa Fe }\end{array}$ & CABA, Córdoba & $\begin{array}{l}\text { Buenos Aires, CABA, } \\
\text { Córdoba }\end{array}$ \\
\hline \multicolumn{4}{|l|}{ Resistance determinants } \\
\hline $\begin{array}{l}\text { 23S rRNA (no. mutated alleles; } \\
\text { total no. isolates) }\end{array}$ & $\begin{array}{c}\mathrm{C} 2611 \mathrm{~T}(4 ; 58) ; \mathrm{C} 2611 \mathrm{~T}(1 ; \\
\text { 1) }\end{array}$ & $\mathrm{C} 2611 \mathrm{~T}(4 ; 12) ; \mathrm{C} 2611 \mathrm{~T}(3 ;$ & A2059G $(4 ; 5)$ \\
\hline MtrR protein (no. isolates) & $\begin{array}{c}\text { A-deletion (12)†; } N \text {. } \\
\text { meningitidis-like (14); G45D } \\
\text { (41); } m \text { tr }_{120}(0) \ddagger\end{array}$ & $\begin{array}{c}\text { A-deletion (6); G45D (3); } \\
m \operatorname{mr}_{120}(0)\end{array}$ & $\begin{array}{l}\text { N. meningitidis-like (4); } \\
\text { G45D (1); mtr }{ }_{120}(0)\end{array}$ \\
\hline Mosaic $m t r$ locus (no. isolates) & $\begin{array}{c}m t r C(14) ; m t r D(14) ; m t r E \\
(13)\end{array}$ & $m t r C(0) ; m t r D(0) ; m \operatorname{trE}(0)$ & $m \operatorname{trC}(4) ; m \operatorname{trD}(4) ; m \operatorname{tr} E(4)$ \\
\hline \multicolumn{4}{|c|}{ 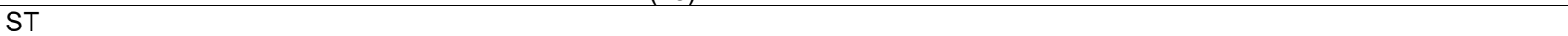 } \\
\hline $\begin{array}{l}N . \text { gonorrhoeae multiantigen } \\
\text { sequence typing (no. isolates) }\end{array}$ & $\begin{array}{l}\text { ST470 (23); ST20102 (7); } \\
\text { ST696 (4); ST12302 (4); } \\
\text { ST11062 (3); other STs (37) }\end{array}$ & $\begin{array}{l}\text { ST18761 (3); ST20104 (3); } \\
\text { singleton STs (7) }\end{array}$ & $\begin{array}{c}\text { ST3935 (2); ST20106 (2); } \\
\text { ST696 (1) }\end{array}$ \\
\hline $\begin{array}{l}\text { Multilocus sequence typing (no. } \\
\text { isolates) }\end{array}$ & $\begin{array}{c}\text { ST1580 (39); ST1584 (10); } \\
\text { ST9363 (10); ST1901 (8); } \\
\text { other STs (11) }\end{array}$ & $\begin{array}{l}\text { ST1901 (6); ST1580 (3); } \\
\text { ST13844 (3); ST13594 (1) }\end{array}$ & ST9363 (4); ST1580 (1) \\
\hline $\begin{array}{l}N . \text { gonorrhoeae sequence typing for } \\
\text { antimicrobial resistance (no. isolates) }\end{array}$ & $\begin{array}{l}\text { ST1038 (30); ST179 (10); } \\
\text { ST168 (5); ST3200 (4); other } \\
\text { STs (29) }\end{array}$ & $\begin{array}{c}\text { ST27 (4); ST2728 (3); } \\
\text { ST1038 (2); singleton STs (4) }\end{array}$ & $\begin{array}{l}\text { ST1993 (2); ST2906 (1); } \\
\text { ST3194 (1); ST3199 (1) }\end{array}$ \\
\hline
\end{tabular}

dominated by isolates from Córdoba $(52.6 \% ; 20 / 38)$ and CABA $(28.9 \% ; 11 / 38)$ but also included isolates obtained in 4 additional provinces. In total, $92.1 \%$ of the clade 1 isolates were from male patients and $7.9 \%$ were from female patients. Clade 1 isolates were characterized by the 23S rRNA C2611T mutation in all 4 alleles and the MtrR G45D amino acid mutation.

Clade 2 comprised 15 isolates that mainly belonged to NG-MAST G12302 (66.7\%) and MLST ST9363 (93.3\%). Clade 2 isolates had a mean SNP difference of 13.1 (range 0-33). All clade 2 isolates were cultured from men. Most $(73.3 \% ; 11 / 15)$ required an MIC of $2 \mu \mathrm{g} / \mathrm{mL}$, and 26.7\% (4/15) required MICs of $\geq 256 \mu \mathrm{g} / \mathrm{mL}$. The first clade 2 isolate was detected in Córdoba in 2016; during 2017-2019, isolates were mainly detected in CABA $(71.4 \% ; 10 / 14)$, except for 2 isolates detected in Córdoba, 1 in Neuquén, and 1 in Buenos Aires. Clade 2 isolates did not have the $23 S$ rRNA C2611T mutation but possessed the mo- saic $m t r R$ promoter and $m t r C D E$ locus. In addition, isolates requiring MICs of $\geq 256 \mu \mathrm{g} / \mathrm{mL}$ had the $23 \mathrm{~S}$ rRNA A2059G mutation in all 4 alleles.

Clade 3 was composed of 10 isolates belonging to NG-MAST G20102 and MLST ST1584. Clade 3 isolates had a mean SNP difference of 1.1 (range 0-2). Eight isolates were collected in Córdoba, 1 in CABA, and 1 in Río Negro during 2017-2019; of these, 8 were from men. All isolates required an MIC of $4 \mu \mathrm{g} / \mathrm{mL}$ and possessed the 23S rRNA C2611T mutation in all 4 alleles.

To investigate the international context of the 2 major MLST STs in Argentina, including azithromycin-resistantST1580 and ST9363, we conducted a phylogenomic analysis using SNPs (Figure 3) (https:/ / microreact.org/project/AZM_Project_2/7a2032e2). The ST1580 isolates from Argentina clustered with isolates from the United States, the United Kingdom (particularly Scotland), Australia, and Brazil. The mean pairwise SNP differences between ST1580

Table 2. Antimicrobial susceptibility of 96 azithromycin-resistant Neisseria gonorrhoeae isolates, Argentina, January 2005-November 2019*

\begin{tabular}{|c|c|c|c|c|c|c|}
\hline \multirow[b]{3}{*}{ Antimicrobial drug } & \multicolumn{6}{|c|}{ Azithromycin MICs, $\mu \mathrm{g} / \mathrm{mL}$ (no. isolates) } \\
\hline & \multicolumn{4}{|c|}{$2-16(91)$} & \multicolumn{2}{|c|}{$\geq 256(5)$} \\
\hline & $\mathrm{MIC}_{50}$ & $\mathrm{MIC}_{90}$ & Range & Resistance, \% & $\mathrm{MIC}$ & Resistance, \% \\
\hline Ciprofloxacin & 0.004 & 16 & $0.001-32$ & 28.6 & $0.002-4$ & 20 \\
\hline Tetracycline & 1 & 2 & $0.125-4$ & 25.3 & $0.5-2$ & 20 \\
\hline Benzylpenicillin & 1 & 2 & $0.25-8$ & 14.3 & $0.5-1$ & 0 \\
\hline Ceftriaxone & 0.004 & 0.03 & $0.002-0.06$ & 0 & $0.004-0.016$ & 0 \\
\hline Cefixime & 0.016 & 0.03 & $0.004-0.125$ & 0 & $0.008-0.03$ & 0 \\
\hline Spectinomycin & 32 & 32 & $16-32$ & 0 & 32 & 0 \\
\hline Gentamicin & 8 & 8 & $4-16$ & 0 & $8-16$ & 0 \\
\hline
\end{tabular}

${ }^{*} \mathrm{MIC}_{50}, \mathrm{MIC}$ for $50 \%$ of isolates; $\mathrm{MIC}_{90}, \mathrm{MIC}$ for $90 \%$ of isolates. 
Year of collection

○ $2001 \bigcirc 2013$

○ 2005 O 2015

○ 2006 O 2016

○ 2008 O 2017

○ 2010 ○ 2018

- 2011 ○ 2019

Provinces

Córdoba $\square$ Neuquén

$\square$ CABA $\square$ La Pampa

$\square$ Buenos Aires $\square$ Santa Fe

$\square$ Rio Negro

Sex

O Male Female O Unknown

Azithromycin MICs

- $2 \mu \mathrm{g} / \mathrm{mL} \quad 16 \mu \mathrm{g} / \mathrm{mL}$

- $4 \mu \mathrm{g} / \mathrm{mL} \square \geq 256 \mu \mathrm{g} / \mathrm{mL}$

- $8 \mu \mathrm{g} / \mathrm{mL}$

C2611T and A2059G mutations

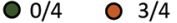

○ $1 / 4 \quad 0 \quad 4 / 4$

MtrR

G45D

N. meningitidis-like promoter

-35 A-deletion

G45D/-35 A-deletion

Wild type

MtrCDE

Mosaic mtrCDE

- Mosaic mtrCD

Wild type

Molecular typing

NG-MAST G470 MLST ST1580 NG-STAR ST1038

NG-MAST G12302 MLST ST9363 NG-STAR ST168

n NG-MAST G20102 M MLST ST1584 NG-STAR ST179
12
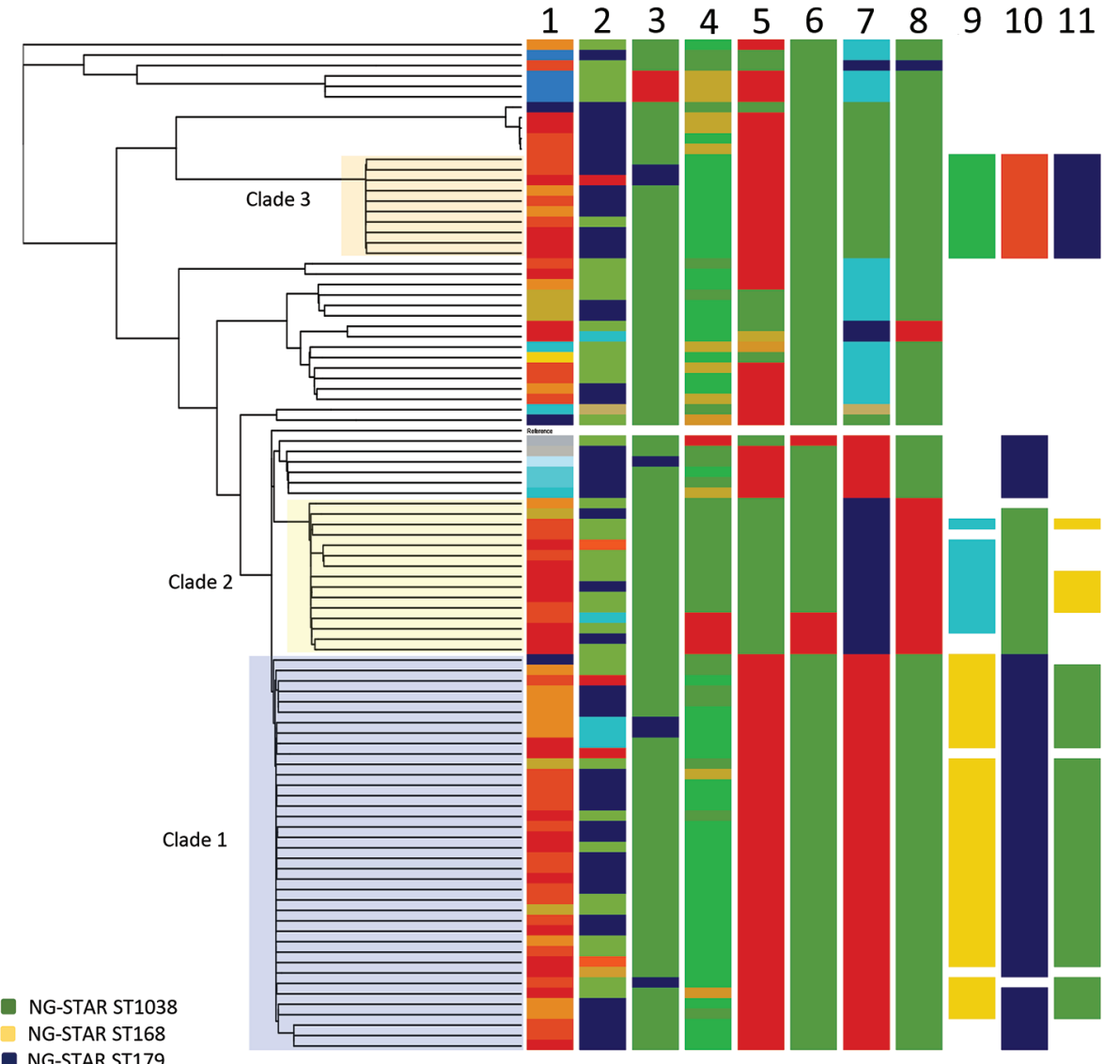

Figure 2. Phylogenomic tree of 96 Neisseria gonorrhoeae isolates with azithromycin MICs of $\geq 2 \mu \mathrm{g} / \mathrm{mL}$, Argentina, January 2005 November 2019. Lane 1, year; lane 2, province; lane 3, sex; lane 4, azithromycin MICs; lane 5, 23S C2611T; lane 6, 23S A25059G; lane 7, MtrR; lane 8, MtrCDE; lane 9, NG-MAST; lane 10, MLST; lane 11, NG-STAR. Scale bar indicates substitutions per site. CABA, Ciudad Autónoma de Buenos Aires; MLST, multilocus sequence typing; NG-MAST, N. gonorrhoeae multiantigen sequence typing; NG-STAR, N. gonorrhoeae sequence typing for antimicrobial resistance; ST, sequence type.

isolates from Argentina and other countries were 6.8 (range 1-23) for the isolates from the United States, 6.9 (range 1-22) for isolates from Australia, 7.9 (range 4-22) for isolates from Scotland, 11.4 (range 4-28) for isolates from Brazil, and 16.8 (range 13-31) for isolates from the United Kingdom (excluding Scotland). Isolates from Scotland and the United Kingdom had MICs of $\geq 256 \mu \mathrm{g} / \mathrm{mL}$ whereas isolates from the United States, Australia, and Brazil had MICs of $2-8 \mu \mathrm{g} / \mathrm{mL}$. All isolates with MICs of $2-8 \mu \mathrm{g} / \mathrm{mL}$ had the 23S rRNA C2611T mutation and all isolates with MICs of $\geq 256 \mu \mathrm{g} / \mathrm{mL}$ had the A2059G mutation. In addition, 2 isolates from Brazil had mosaic $m \operatorname{tr} D$ alleles, but no mutations in the $23 \mathrm{~S}$ rRNA gene; these isolates had MICs of $2 \mu \mathrm{g} / \mathrm{mL}$. The ST9363 isolates from Argentina clustered with other ST9363 isolates from the United States, Australia, Canada, Brazil, and Norway. ST9363 isolates from Argentina had a mean pairwise SNP difference of 7.7 (range 0-20) with isolates from Brazil, 10.1 (range 1-23) with isolates from Norway, 12.5 (range 5-25) with isolates from Canada, 13.1 ( range 2-42) with isolates from the United States, and 14.8 (range 2-35) with isolates from Australia. All isolates had mosaic $m t r R$ promoters and $m t r D$ alleles. All isolates with MICs of $\geq 256 \mu \mathrm{g} / \mathrm{mL}$ had the $23 \mathrm{~S} \mathrm{rRNA}$ A2059G mutation and 4 isolates with MICs of 8-16 $\mu \mathrm{g} / \mathrm{mL}$ had the 23S rRNA C2611T mutation.

\section{Conclusion}

We characterized the genomes of azithromycin-resistant $N$. gonorrhoeae isolates collected in Argentina during 2005-2019. Phylogenomic analysis showed that isolates from Argentina clustered into distinct clades, including 3 clades comprising $63(65.6 \%)$ isolates collected during 2016-2019. All isolates also were 
resistant to benzylpenicillin, tetracycline, ciprofloxacin or some combination, but susceptible to ceftriaxone and cefixime.

In Argentina, dual therapy is recommended as firstline treatment for uncomplicated gonorrhea, according to the WHO guidelines (6). The Argentine Ministry of Health and the Sociedad Argentina de Infectología recommend a single 1-g dose of azithromycin monotherapy for the treatment of Chlamydia trachomatis and Mycoplasma genitalium infections $(41,42)$. These guidelines also recommend antimicrobial treatment for suspected infections. Azithromycin has a long half-life, resulting in detectable drug concentrations in human plasma for up to 14 days (43). Undiagnosed N. gonorrhoeae infections concurrent with the treatment of $C$. trachomatis and M. genitalium infections might lead to prolonged exposure to subinhibitory concentrations of azithromycin, thereby prompting the induction of or selection for resistance genes. In the United States and United Kingdom, dual therapy is no longer the first-line treatment. Instead, high-dose ceftriaxone monotherapy (500 $\mathrm{mg}$ in the United States or $1 \mathrm{~g}$ in the United Kingdom) is now recommended for treatment of uncomplicated gonorrhea $(44,45)$. Moreover, additional treatment with doxycycline $(100 \mathrm{mg} 2 \times / \mathrm{d}$ for $7 \mathrm{~d})$ is recommended if chlamydial infection has not been excluded (44). Similar empirical antimicrobial therapies for gonorrhea and chlamydial infections might be of benefit in Argentina to reduce patient exposure to azithromycin and avoid the emergence of resistant gonococcal strains.

Azithromycin resistance (i.e., MICs of $\geq 2 \mu \mathrm{g} / \mathrm{mL}$ ) in $N$. gonorrhoeae has been mainly associated with mutations in the 23S rRNA target (38). The 23S rRNA A2059G mutation causes high-level resistance (i.e., MICs of $\geq 256$ $\mu \mathrm{g} / \mathrm{mL}$ ) and the C2611T mutation causes low-level resistance (i.e., MICs of $2-16 \mu \mathrm{g} / \mathrm{mL}$ ) (38). We found that $75 \%$ of isolates had the C2611T mutation. These isolates were phylogenetically diverse; however, clade 1, which was predominated by MLST ST1580 and NGMAST G470, comprised 38 (52.8\%) isolates. NG-MAST ST470 has been associated with high-level resistance to azithromycin in Scotland (18). In addition, NG-MAST ST470 has $>99 \%$ similarity to ST9768, which caused an outbreak of high-level azithromycin-resistant N. gonorrhoeae in the United Kingdom (16). Previous gonococcal evolution studies have estimated that $\approx 4$ (range $0-14$ ) SNPs occur per year per genome, enabling phylogenetic analysis (21). Isolates from Argentina differed from isolates from Scotland by $\geq 4$ (mean 7.9) SNPs and the United Kingdom by 13 (mean 16.8) SNPs. In addition,

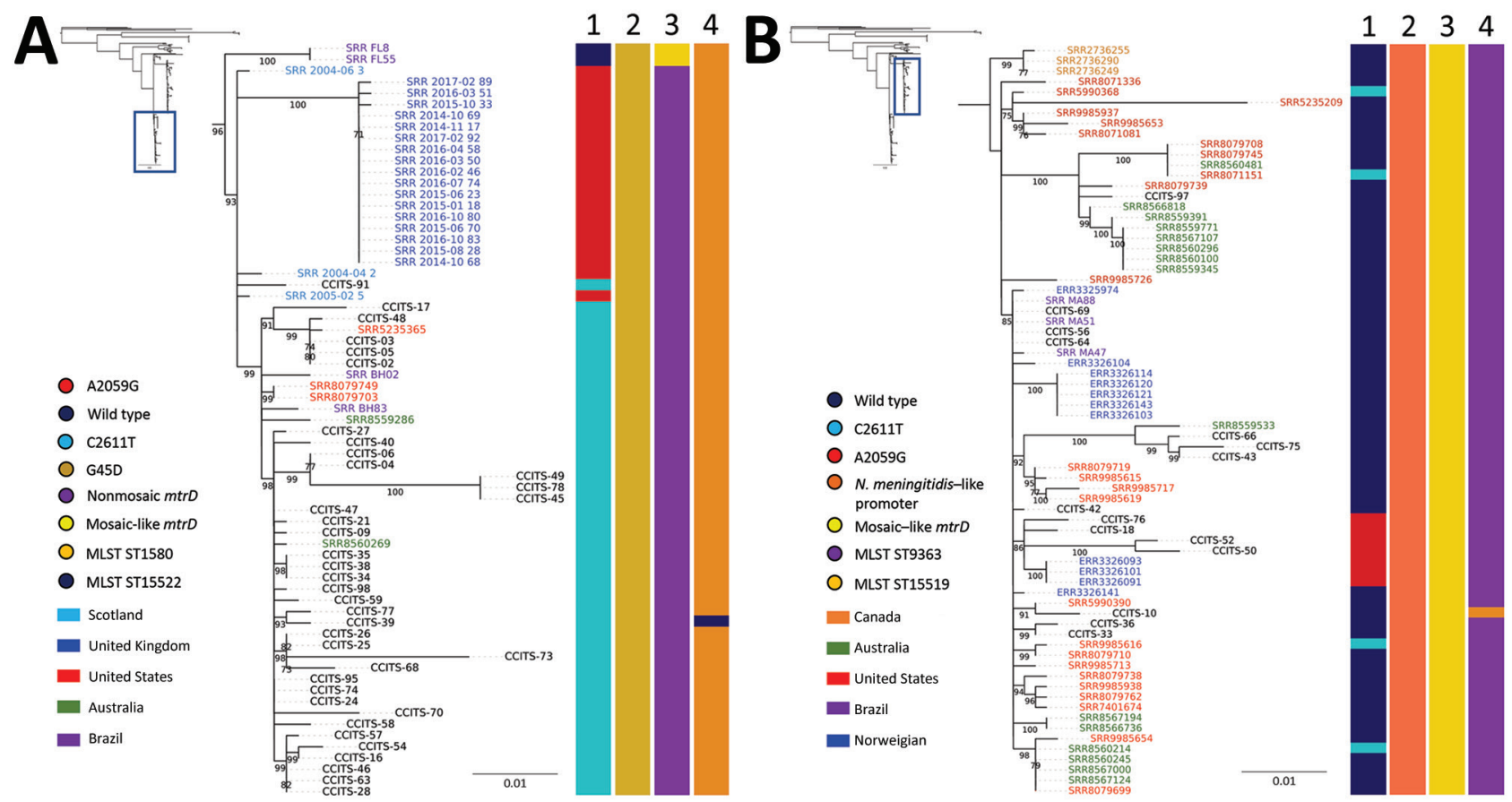

Figure 3. Phylogenomic tree of Neisseria gonorrhoeae isolates with azithromycin MICs of $\geq 2 \mu \mathrm{g} / \mathrm{mL}, 2004-2017$. A) MLST ST1580 and NG-MAST genogroup 470 isolates from Argentina in the context of selected isolates from Scotland (2004-2005), the United States (2016), Australia (2017), Brazil (2015-2016), and the United Kingdom (2014-2017). B) MLST ST9363 and NG-MAST genogroup G12302 isolates from Argentina in the context of selected isolates from Australia (2017), the United States (2014-2017), Brazil (2015-2016), Norway (2017), and Canada (2013-2014). Lane 1, 23 S rRNA; lane 2, mtrR; lane 3, mtrD; lane 4, MLST. Labels indicate isolate identity; font colors indicate country of isolation. Bar colors indicate distribution of mutations. Insets indicate relationship of sequences to larger phylogenetic tree. Scale bar indicates substitutions per site. MLST, multilocus sequence typing; NG-MAST, N. gonorrhoeae multiantigen sequence typing. 
NG-MAST ST470 isolates from the United States, Brazil, and Australia, all of which showed low-level resistance to azithromycin, were closely related to isolates from Argentina (mean 7-11 SNPs). These findings support the hypothesis that NG-MAST G470 strains from Argentina might be descended from 1 lineage of the ST470 clone, which has spread internationally and can develop high-level and low-level resistance to azithromycin. Previous research, especially that of Unemo et al. (38), hypothesized that gonococcal antimicrobial-resistant strains emerge through genetic events, such as horizontal gene transfer or spontaneous mutations; these strains can spread quickly within a geographic region through sexual networks. Furthermore, compensatory mutations or gene exchange might have preserved this lineage in Argentina. The presence of additional STs, such as the co-circulation of MLST ST1584 and MLST ST1580 (NG-MAST G470), suggests that novel introductions also have occurred.

The $m t r$ locus recently has been described as a hotspot for genetic recombination; mosaic-like $m t r$ loci are associated with decreased susceptibility to azithromycin (i.e., MICs of $1-4 \mu \mathrm{g} / \mathrm{mL}$ ) and contribute to the survival and transmission of $N$. gonorrhoeae $(39,40,46)$. Most clade 2 isolates were associated with MLST ST9363 and had a mosaic-like $m t r$ locus. MLST ST9363 was the predominant strain type of isolates with MICs of 2-4 $\mu \mathrm{g} / \mathrm{mL}$ identified in Australia during 2017 and the United States during 2014-2017 $(24,25,35)$. We found that MLST ST9363 isolates from Argentina shared a high level of genomic similarity with the ST9363 clones reported in Australia, the United States, Canada, Norway, and Brazil, indicating that importation and dissemination has occurred. Those data further support the hypothesis that $N$. gonorrhoeae isolates carrying a mosaic-like $\mathrm{mtr}$ locus contribute to the emergence of isolates with low-level resistance to azithromycin in many countries $(24,25)$. Isolates with MICs of $\geq 256 \mu \mathrm{g} / \mathrm{mL}$ have recently reemerged in Argentina (20). Those isolates belonged to clade 2 and were distinguished by the mosaic-like $m t r$ locus and the A2059G mutation in all 4235 rRNA gene alleles. The phylogenetic tree showed that these isolates were closely related to isolates from Norway (mean 10.2 SNPs) that also had MICs of $\geq 256 \mu \mathrm{g} / \mathrm{mL}$, suggesting that strains carrying a mosaic-like $m t r$ locus and 23S rRNA A2059G mutation can disseminate internationally. Previous studies have suggested that isolates carrying the A2059G mutation or mosaic mtr locus have enhanced fitness; elucidating the effects of both mechanisms on $N$. gonorrhoeae evolution might help predict the emergence and spread of azithromycin resistance $(39,46,47)$.
Because we received a small number of isolates from some provinces, our dataset might have been limited by selection bias. In addition, we did not have access to therapy strategies and treatment success rates, which might have provided insight into the generation of resistance or the selection of azithromycin-resistant isolates. Finally, we obtained limited data regarding patients' sexual orientation and HIV status, but found that clade 2 strains were slightly more associated with male patients, including men who have sex with men, than clade 1 strains (100.0\% vs. $92.1 \%)$. In addition, 3 patients who had infections caused by clade 2 strains were HIV-positive (data not shown). Increased awareness of the transmission dynamics of azithromycin-resistant gonococcal strains within sexual networks is crucial to confirming these observations. Continuing surveillance of the prevalence and distribution of azithromycin-resistant strains in addition to genomic monitoring using individual-level epidemiologic data should provide a more complete picture of azithromycin-resistant gonococcal strains. These data will inform public health strategies to control azithromycin-resistant $N$. gonorrhoeae.

In conclusion, the recent increase in the prevalence of azithromycin-resistant N. gonorrhoeae isolates in Argentina was mainly the result of the introduction and expansion of 2 clones belonging to MLST ST1580 and ST9363. The integration of appropriate STI diagnosis and antimicrobial prescription into health services combined with genomic, phenotypic, and epidemiologic gonococcal surveillance data will be critical in preventing the dissemination of gonococcal clones resistant to azithromycin, ceftriaxone, or both, and preserving the current available therapeutic option for gonorrhea.

Members of the Gonococcal Antimicrobial Susceptibility Surveillance Programme - Argentina: C. Oviedo, P. Cristaldo, M. Gonzalez, L. Fernández Canigia, J. Smayevski, M. Turco, C. Garbaz, M. Morales, C. Alfonso, M. Montoto, M. Marcato, M. Cervetto, M. Giovanakis, L. Scocozza, L. Cardozo, N. Prieto, A. Tarzia, V. Cames, L. Spadaccini, M. Machaín, M. Garrone, V. Vilches, M. Sparo, A. Tognieri, M. Rizzo, N. Casanova, G. Sly, O. Mariñasqui, P. Simone, L. Moreno, S. Odriz, T. Lopez, J. Valles, V Manías, A. Brihuela, H. Solís, A. Burzla, V. Silva, N. Sponton, A. Berejnoi, V. Guillermel, G. Rivollier, M. Roncallo, M. Alvarez, M. Flores, A. Pereyra, N. Scarone, F. Ampuero, C. Bandoni, A.C. Lopez, A. Lopez, W. Krause, N. Pereyra, N. Yoya, A Prestifilippo, L. Basco, N. Cudmani, M. Mernes, P. Ranea, M. Vargas, R. Pato, G. Bello Velázquez, and S. Roginski.

\section{Acknowledgments}

We are grateful to Beatriz Lopez for her commentary on the manuscript. 
The study was supported by grants from the Genomics and Bioinformatics Platform, Instituto Nacional de Enfermedades Infecciosas - Administración Nacional de Laboratorios e Institutos de Salud Dr. Carlos G. Malbrán (Ciudad Autónoma de Buenos Aires, Argentina), the Programa de Becas de Formación en el Exterior en Ciencia y Tecnología (grant no. Grant Bec.Ar - CIT; Ciudad Autónoma de Buenos Aires), and the Örebro County Council Research Committee and the Foundation for Medical Research at Örebro University Hospital (Örebro, Sweden).

\section{About the Author}

Mr. Gianecini is a microbiologist at the Instituto Nacional de Enfermedades Infecciosas - Administración Nacional de Laboratorios e Institutos de Salud Dr. Carlos G. Malbrán in la Ciudad Autónoma de Buenos Aires, Argentina. His primary research interests include public health and antimicrobial resistance.

\section{References}

1. Rowley J, Vander Hoorn S, Korenromp E, Low N, Unemo M, Abu-Raddad LJ, et al. Chlamydia, gonorrhoea, trichomoniasis and syphilis: global prevalence and incidence estimates, 2016. Bull World Health Organ. 2019;97:548-562P. https:/ / doi.org/10.2471/BLT.18.228486

2. Wi T, Lahra MM, Ndowa F, Bala M, Dillon JR, Ramon-Pardo P, et al. Antimicrobial resistance in Neisseria gonorrhoeae: global surveillance and a call for international collaborative action. PLoS Med. 2017;14:e1002344. https://doi.org/10.1371/journal.pmed.1002344

3. Unemo M, Lahra MM, Cole M, Galarza P, Ndowa F, Martin I, et al. World Health Organization Global Gonococcal Antimicrobial Surveillance Program (WHO GASP): review of new data and evidence to inform international collaborative actions and research efforts. Sex Health. 2019;16:412-25. https:/ / doi.org/10.1071/SH19023

4. Unemo M. Current and future antimicrobial treatment of gonorrhoea - the rapidly evolving Neisseria gonorrhoeae continues to challenge. BMC Infect Dis. 2015;15:364. https:/ / doi.org/10.1186/s12879-015-1029-2

5. Unemo M, Ross J, Serwin AB, Gomberg M, Cusini M, Jensen JS. 2020 European guideline for the diagnosis and treatment of gonorrhoea in adults. Int J STD AIDS. 2020;2020:956462420949126.

6. World Health Organization. WHO guidelines for the treatment of Neisseria gonorrhoeae. 2016 [cited 2020 Dec 4]. http://www.who.int/reproductivehealth/publications/ rtis/gonorrhoea-treatment-guidelines/en

7. Fifer H, Natarajan U, Jones L, Alexander S, Hughes G, Golparian D, et al. Failure of dual antimicrobial therapy in treatment of gonorrhoea. N Engl J Med. 2016;374:2504-6. https://doi.org/10.1056/NEJMc1512757

8. Whiley DM, Jennison A, Pearson J, Lahra MM. Genetic characterisation of Neisseria gonorrhoeae resistant to both ceftriaxone and azithromycin. Lancet Infect Dis. 2018;18:7178. https:/ / doi.org/10.1016/S1473-3099(18)30340-2

9. Eyre DW, Sanderson ND, Lord E, Regisford-Reimmer N, Chau K, Barker L, et al. Gonorrhoea treatment failure caused by a Neisseria gonorrhoeae strain with combined ceftriaxone and high-level azithromycin resistance, England,
February 2018. Euro Surveill. 2018;23:1800323. https:/ / doi.org/ 10.2807/1560-7917.ES.2018.23.27.1800323

10. Jennison AV, Whiley D, Lahra MM, Graham RM, Cole MJ, Hughes G, et al. Genetic relatedness of ceftriaxone-resistant and high-level azithromycin resistant Neisseria gonorrhoeae cases, United Kingdom and Australia, February to April 2018. Euro Surveill. 2019;24:1900118. https:/ / doi.org/ 10.2807/1560-7917.ES.2019.24.8.1900118

11. Williamson DA, Fairley CK, Howden BP, Chen MY, Stevens K, De Petra V, et al. Trends and risk factors for antimicrobial-resistant Neisseria gonorrhoeae, Melbourne, Australia, 2007 to 2018. Antimicrob Agents Chemother. 2019;63:e01221-19. https:// doi.org/10.1128/AAC.01221-19

12. US Centers for Disease Control and Prevention. Sexually transmitted disease surveillance 2017. 2018 [cited 2020 Dec 4]. https://www.cdc.gov/std/stats17/2017-STDSurveillance-Report_CDC-clearance-9.10.18.pdf

13. Thakur SD, Araya P, Borthagaray G, Galarza P, Hernandez AL, Payares D, et al. Resistance to ceftriaxone and azithromycin in Neisseria gonorrhoeae isolates from 7 countries of South America and the Caribbean: 2010-2011. Sex Transm Dis. 2017;44:157-60. https:/ / doi.org/10.1097/ OLQ.0000000000000587

14. Ministerio de Salud y Desarrollo Social. Bulletin on HIV/ AIDS and STIS in Argentina no. 36 [in Spanish]. 2019 [cited 2020 Dec 4]. https:/ / bancos.salud.gob.ar/recurso/ boletin-sobre-el-vih-sida-e-its-en-la-argentina-ndeg-36

15. Clinical and Laboratory Standards Institute. 2019. Performance standards for antimicrobial susceptibility testing: twenty-ninth informational supplement (M100-S29). Wayne (PA): The Institute; 2019.

16. Fifer H, Cole M, Hughes G, Padfield S, Smolarchuk C, Woodford N, et al. Sustained transmission of high-level azithromycin-resistant Neisseria gonorrhoeae in England: an observational study. Lancet Infect Dis. 2018;18:573-81. https:/ / doi.org/10.1016/S1473-3099(18)30122-1

17. Demczuk W, Martin I, Peterson S, Bharat A, Van Domselaar G, Graham M, et al. Genomic epidemiology and molecular resistance mechanisms of azithromycin-resistant Neisseria gonorrhoeae in Canada from 1997 to 2014. J Clin Microbiol. 2016;54:1304-13. https:/ / doi.org/10.1128/JCM.03195-15

18. Palmer HM, Young H, Winter A, Dave J. Emergence and spread of azithromycin-resistant Neisseria gonorrhoeae in Scotland. J Antimicrob Chemother. 2008;62:490-4. https://doi.org/10.1093/jac/dkn235

19. Jacobsson S, Golparian D, Cole M, Spiteri G, Martin I, Bergheim T, et al. WGS analysis and molecular resistance mechanisms of azithromycin-resistant (MIC $>2 \mathrm{mg} / \mathrm{L}$ ) Neisseria gonorrhoeae isolates in Europe from 2009 to 2014. J Antimicrob Chemother. 2016;71:3109-16. https:/ / doi.org/ 10.1093/jac/dkw279

20. Galarza PG, Alcalá B, Salcedo C, Canigia LF, Buscemi L, Pagano I, et al. Emergence of high level azithromycinresistant Neisseria gonorrhoeae strain isolated in Argentina. Sex Transm Dis. 2009;36:787-8. https:/ / doi.org/10.1097/ OLQ.0b013e3181b61bb1

21. De Silva D, Peters J, Cole K, Cole MJ, Cresswell F, Dean G, et al. Whole-genome sequencing to determine transmission of Neisseria gonorrhoeae: an observational study. Lancet Infect Dis. 2016;16:1295-303. https://doi.org/10.1016/ S1473-3099(16)30157-8

22. Harris SR, Cole MJ, Spiteri G, Sánchez-Busó L, Golparian D, Jacobsson S, et al.; Euro-GASP study group. Public health surveillance of multidrug-resistant clones of Neisseria gonorrhoeae in Europe: a genomic survey. Lancet Infect Dis. 2018;18:758-68. https:/ / doi.org/10.1016/S1473-3099(18)30225-1 
23. Grad YH, Harris SR, Kirkcaldy RD, Green AG, Marks DS, Bentley SD, et al. Genomic epidemiology of gonococcal resistance to extended-spectrum cephalosporins, macrolides, and fluoroquinolones in the United States, 2000-2013. J Infect Dis. 2016;214:1579-87. https://doi.org/10.1093/infdis/jiw420

24. Williamson DAF, Chow EPF, Gorrie CL, Seemann T, Ingle DJ, Higgins $\mathrm{N}$, et al. Bridging of Neisseria gonorrhoeae lineages across sexual networks in the HIV pre-exposure prophylaxis era. Nat Commun. 2019;10:3988. https:/ / doi.org/10.1038/ s41467-019-12053-4

25. Gernert KM, Seby S, Schmerer MW, Thomas JC IV, Pham CD, St Cyr S, et al.; Antimicrobial-Resistant Neisseria gonorrhoeae Working Group. Azithromycin susceptibility of Neisseria gonorrhoeae in the USA in 2017: a genomic analysis of surveillance data. Lancet Microbe. 2020;1:e154-64. https:/ / doi.org/10.1016/S2666-5247(20)30059-8

26. Gianecini RA, Zittermann S, Oviedo C, Galas M, Pardo PR, Allen VG, et al. Use of whole genome sequencing for the molecular comparison of Neisseria gonorrhoeae isolates with decreased susceptibility to extended spectrum cephalosporins from 2 geographically different regions in America. Sex Transm Dis. 2019;46:548-55. https:/ / doi.org/ 10.1097/OLQ.0000000000001011

27. World Health Organization. Laboratory diagnosis of sexually transmitted infections, including human immunodeficiency virus. 2013 [cited 2020 Dec 4]. http:/ / apps.who.int/iris/ bitstream/10665/85343/1/9789241505840_eng.pdf

28. Gianecini RA, Golparian D, Zittermann S, Litvik A, Gonzalez S, Oviedo C, et al.; Gonococcal Antimicrobial Susceptibility Surveillance Programme-Argentina Working Group. Genome-based epidemiology and antimicrobial resistance determinants of Neisseria gonorrhoeae isolates with decreased susceptibility and resistance to extended-spectrum cephalosporins in Argentina in 2011-16. J Antimicrob Chemother. 2019;74:1551-9. https://doi.org/10.1093/jac/dkz054

29. Hunt M, Mather AE, Sánchez-Busó L, Page AJ, Parkhill J, Keane JA, et al. ARIBA: rapid antimicrobial resistance genotyping directly from sequencing reads. Microb Genom. 2017;3:e000131. https:// doi.org/10.1099/mgen.0.000131

30. Martin IM, Ison CA, Aanensen DM, Fenton KA, Spratt BG. Rapid sequence-based identification of gonococcal transmission clusters in a large metropolitan area. J Infect Dis. 2004;189:1497-505. https:/ / doi.org/10.1086/383047

31. Demczuk W, Sidhu S, Unemo M, Whiley DM, Allen VG, Dillon JR, et al. Neisseria gonorrhoeae sequence typing for antimicrobial resistance, a novel antimicrobial resistance multilocus typing scheme for tracking global dissemination of N. gonorrhoeae strains. J Clin Microbiol. 2017;55:1454-68. https://doi.org/10.1128/JCM.00100-17

32. Nguyen LT, Schmidt HA, von Haeseler A, Minh BQ. IQ-TREE: a fast and effective stochastic algorithm for estimating maximum-likelihood phylogenies. Mol Biol Evol. 2015;32:268-74. https://doi.org/10.1093/molbev/msu300

33. Hadfield J, Croucher NJ, Goater RJ, Abudahab K, Aanensen DM, Harris SR. Phandango: an interactive viewer for bacterial population genomics. Bioinformatics. 2018;34:292-3.

34. Pommier T, Canbäck B, Lundberg P, Hagström A, Tunlid A. RAMI: a tool for identification and characterization of phylogenetic clusters in microbial communities. Bioinformatics. 2009;25:736-42. https:// doi.org/10.1093/ bioinformatics/btp051

35. Thomas JC, Seby S, Abrams AJ, Cartee J, Lucking S, Vidyaprakash E, et al.; Antimicrobial-Resistant Neisseria gonorrhoeae Working Group. Evidence of recent genomic evolution in gonococcal strains with decreased susceptibility to cephalosporins or azithromycin in the United States,
2014-2016. J Infect Dis. 2019;220:294-305. https://doi.org/ 10.1093/infdis/jiz079

36. Golparian D, Bazzo ML, Golfetto L, Gaspar PC, Schörner MA, Schwartz Benzaken A, et al.; Brazilian GASP Network. Genomic epidemiology of Neisseria gonorrhoeae elucidating the gonococcal antimicrobial resistance and lineages/sublineages across Brazil, 2015-16. J Antimicrob Chemother. 2020;75:3163-72. https://doi.org/10.1093/jac/dkaa318

37. Alfsnes K, Eldholm V, Olsen AO, Brynildsrud OB, Bohlin J, Steinbakk M, et al. Genomic epidemiology and population structure of Neisseria gonorrhoeae in Norway, 2016-2017. Microb Genom. 2020;6:e000359. https://doi.org/10.1099/ mgen.0.000359

38. Unemo M, Shafer WM. Antimicrobial resistance in Neisseria gonorrhoeae in the 21st century: past, evolution, and future. Clin Microbiol Rev. 2014;27:587-613. https:/ / doi.org/ 10.1128/CMR.00010-14

39. Wadsworth CB, Arnold BJ, Sater MRA, Grad YH. Azithromycin resistance through interspecific acquisition of an epistasis-dependent efflux pump component and transcriptional regulator in Neisseria gonorrhoeae. MBio. 2018;9:e01419-18. https://doi.org/10.1128/mBio.01419-18

40. Rouquette-Loughlin CE, Reimche JL, Balthazar JT, Dhulipala V, Gernert KM, Kersh EN, et al. Mechanistic basis for decreased antimicrobial susceptibility in a clinical isolate of Neisseria gonorrhoeae possessing a mosaic-like mtr efflux pump locus. MBio. 2018;9:e2281-18. https:/ / doi.org/10.1128/mBio.02281-18

41. Ministerio de salud y ambiente de la nación. Management guide for sexually transmitted infections [in Spanish]. Buenos Aires: El Ministerio; 2004.

42. Sociedad Argentina de Infectología. First consensus on the diagnosis, treatment, and prevention of sexually transmitted infections [in Spanish]. 2011 [cited 2020 Dec 4]. https:/ / drive. google.com/file/d/1VqW7USdEyO5FkJXwB239f8pudQ9Mb DUr/view

43. Kong FYS, Horner P, Unemo M, Hocking JS. Pharmacokinetic considerations regarding the treatment of bacterial sexually transmitted infections with azithromycin: a review. J Antimicrob Chemother. 2019;74:1157-66. https://doi.org/10.1093/jac/dky548

44. St Cyr S, Barbee L, Workowski KA, Bachmann LH, Pham C, Schlanger K, et al. Update to CDC's treatment guidelines for gonococcal infection, 2020. MMWR Morb Mortal Wkly Rep. 2020;69:1911-6. https:/ / doi.org/10.15585/mmwr.mm6950a6

45. Fifer H, Saunders J, Soni S, Sadiq ST, FitzGerald M. 2018 UK national guideline for the management of infection with Neisseria gonorrhoeae. Int J STD AIDS. 2020;31:4-15. https://doi.org/10.1177/0956462419886775

46. Handing JW, Ragland SA, Bharathan UV, Criss AK. The MtrCDE efflux pump contributes to survival of Neisseria gonorrhoeae from human neutrophils and their antimicrobial components. Front Microbiol. 2018;9:2688. https:/ / doi.org/ 10.3389/fmicb.2018.02688

47. Zhang J, van der Veen S. Neisseria gonorrhoeae $23 \mathrm{~S}$ rRNA A2059G mutation is the only determinant necessary for high-level azithromycin resistance and improves in vivo biological fitness. J Antimicrob Chemother. 2019;74:407-15. https://doi.org/10.1093/jac/dky438

Address for correspondence: Patricia Galarza, National Institute of Infectious Diseases - ANLIS Dr. Carlos G. Malbrán, Velez Sarsfield 563, C1282AFF, Ciudad Autónoma de Buenos Aires,

Argentina; email: pgalarza@anlis.gob.ar. 